\title{
24 OPEN INNOVATION AND THE EROSION OF THE TRADITIONAL INFORMATION SYSTEMS PROJECT'S BOUNDARIES
}

\author{
Amany Elbanna \\ Lougborough University \\ Leicestershire, U.K.
}

\begin{abstract}
This paper examines the notion of open innovation and its implication on information systems management. It investigates a project of an enterprise resource planning system implementation in an international organization to unravel the resemblance with the open innovation model. The study shows that the conceptualization of ERP project as an open innovation could reveal the complex architecture of today's organization from which the ERP project cannot be isolated. It argues that the traditional boundaries around IS projects are dissolving and the relationship between what used to be outside and what used to be inside the project is increasingly blurred. The study calls for a different perspective of project management that goes beyond single and multiple project management to scan the open space of innovation and actively look for partners, competitors, and collaborators.
\end{abstract}

Keywords Open innovation, IS project management, IS multiple projects environment, ERP

\section{INTRODUCTION}

Organizations are facing fierce competition and a changing global market that requires them to constantly innovate to survive and protect their market share. The innovation process within the organization attracts scholars who mainly focus on studying the process of research and development and how organizations could provide an environ-

Please use the following format when citing this chapter:

Elbanna, A., 2008, in IFIP International Federation for Information Processing, Volume 287, Open IT-Based Innovation: Moving Towards Cooperative IT Transfer and Knowledge Diffusion, eds. León, G., Bernardos, A., Casar, J., Kautz, K., and DeGross, J. (Boston: Springer), pp. 423-439. 
ment that fosters innovation, detect it, and benefit from it. Recently, scholars have started to sense some changes in the innovation process. After reviewing the development of the R\&D innovation process and classify it into four different generations, Rothwell (1994) concluded that we are entering a fifth generation innovation. He characterizes this fifth generation of innovation process to be "essentially lean," where "innovation is becoming more of a networking process" (p. 22). Gibbons et al. (1994) have also discussed the changing mode of knowledge in what they called "mode 2." They admit that it is unfolding and evolving and hence its characteristics and implications are far from clear at the point of writing and that their ideas are early attempts to detect the change. In mode 2, they argue, "knowledge is accumulated through the repeated configuration of human resources in flexible, essentially transient forms of organization" (p. 9). Chesbrough (2003) also detected the change in the R\&D innovation process and argued that organizations are facing a new paradigm in innovation and coined it open innovation. Open innovation denies the closed boundaries around the innovation and the views that organizational innovation is an internal matter that needs to be isolated and protected. Chesbrough argues that innovation is distributed as knowledge and calls for the opening up of organizational boundaries to include external sources of innovation. There is also a growing body of research that links the process of innovation to network arrangements, yet focuses on R\&D networks within and between organizations (Swan and Scarbrough 2005).

Despite the different names - open innovation, networked innovation, mode 2, or ffifth generation - there is a common sense of change in the R\&D innovation process and different authors try to sketch the changes and their implications. The general theme underlying these studies is that organizations cannot continue to look inward in their innovation process, isolating themselves from possible collaborators, partners, and competitors. Another theme is that innovation knowledge does not necessarily entirely lie within the organization and there are other several ways to gain knowledge from the outside. A last theme is that the innovation process has to be flexible and lean to cope with changes in the business platform. In short, open innovation invites the organizations to break from its innovation silo and open up its boundaries to achieve a flexible and lean innovation.

Information systems has been long recognized as an organization innovation (Wynn and Fitzgerald 2004). Studies have explored the process of IS innovation within the organizations, the diffusion of IS innovation, and the role of IS/IT in organizational innovation (Henriksen and Kautz 2006). The process oriented studies of IS innovation tend to adopt a single project focus that looks inward into the innovation process within a certain project. This single project focus is also shared by the majority of project management literature (Payne 1995). This is despite reports that organizations are increasingly under competitive pressures to innovate and introduce change, which is usually done through projects, and therefore modern organizations are increasingly involved in several projects at the same time (Masini and Pich 2004). It is estimated that up to 90 percent of projects in general are carried out in a multiple project environment (Payne 1995, Dooley et al. 2005). However, little is known about the implications of such a busy platform on IS projects.

This paper aims to explore the notion of open innovation, its applicability and implications in the busy multiple-project platform that current IS innovations face in the software context. To this end, the study examines an enterprise resource planning imple- 
mentation project in an international postage and packaging organization. It goes beyond the traditional project management view that focuses on managing budget and time to reveal the busy organizational platform through which an IS project could be run.

Following the introduction, the paper proceeds as follows. The second section discusses the project organization in software development and, in particular, packaged software. The third section presents the resemblance between actor network theory (ANT) and open innovation ideas. The fourth section presents the research methodology and the background of the case study. The fifth section presents the findings of the case. The sixth section discusses the findings and their implication.

\section{PACKAGED SOFTWARE PROJECT MANAGEMENT}

Packaged software development (in software houses) and implementation (in the buyer organization) usually take place in a pure project organization, a separate, largely self-contained entity that is devoted exclusively to achieving the project aims and that will be disbanded when the project is completed or abandoned (Garrety et al. 2004; Hobday 2000; Meredith and Mantel 1995). This ad hoc organization of projects is separated administratively from the rest of the organization, reflecting a division of labor between projects and routine operations. The management of packaged software projects has received the attention of researchers who traditionally tended to study the vendor's experience of software development and recently the implementation project in the buyer organization. In both cases, researchers tended to adopt a single project perspective in their studies of software projects. This perspective focuses solely on the single project under study and the internal dynamics of innovation. This view respects the traditional boundaries around an IS project that clearly and strictly differentiates between what is in the realm of the project and what is outside.

The single project perspective reflected in the packaged software projects literature produces valuable insight, but misses the complexity of today's organizations and their ongoing practice of having several projects running at any point of time. Overlooked in the literature, the multiple project perspective is recognized in project management

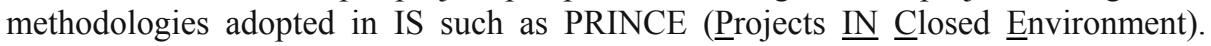
PRINCE accommodates a multiple project management perspective while maintaining a closed innovation view that is based on bundling related IS projects under the governance of a central body, called a program, in order to allocate resources and ensure compliance with a schedule (Olson 2004). It is in this bundling that programs get separated from each other and it is for a central IS body within the organization to manage the IS portfolio of programs and allocate resources between them. It should be noted here that project management methodologies are based on the consolidation and monitoring of a project plan that is a combination of an organization plan and a project schedule. The organization plan consists of two activities: (1) a work breakdown structure (WBS) to define the tasks required and the aim of each one as well as their interdependencies, and (2) an organization breakdown structure (OBS) to allocate roles to the WBS defined tasks. Project management tools such as critical path methods or Gantt charts are then used to schedule projects (Cijsouw et al. 2007; Steyn 2002).

Studies of multiple project environments are rather scarce. Evaristo and van Fenema (1999) agree that the overwhelming number of projects presented in the literature as well 
as most of the practical and theoretical developments on projects are centered on single projects. They tried to reveal the complexity of current projects, presenting a classification of projects based on the number of projects and sites involved. In addition to the simple single and multiple projects categories, they introduced categories such as colocated program, multiple colocated programs, distributed projects, and multiple distributed projects in shared or discreet locations. In a different but related front, Desouza and Evaristo (2004) studied the knowledge management needs in non-colocated work environments. They applied Damm and Schindler's (2002) categorization of project knowledge: knowledge in projects, knowledge about projects, and knowledge from projects to suggest the need for a hybrid approach to project knowledge management. Knowledge in project means knowledge generated inside a project such as schedule, milestones, meeting minutes, and training manuals. Knowledge about projects refers to organizational need to keep an inventory of all projects to aid planning and controlling such as employees assignment to projects, return on investment, cost and benefit analysis, deadlines, and customer commitments and expectations. Knowledge from projects is a post hoc analysis and audit of key insight generated from carrying out projects. Damm and Schindler's proposed hybrid approach consists of a central repository to hold knowledge about and from projects and individual repositories available to peers. This view recognizes the different needs of project-related information yet it is limited to a traditional view of project knowledge that focuses on scheduling and allocation of resources, typically financial and human resources. Moreover, knowledge in projects is suggested to be kept individually and exchanged between individual projects upon request on a peer-to-peer basis. This proposition assumes that individual projects are aware of other projects and hence recognizes particular information needs from other projects. Currently, this proposition is not well grounded and has no evidence to support it. Desouza and Evaristo do not provide any empirical evidence to support this assumption. On the other hand, the current project and program management organization maintains strict boundaries between projects that do not support this view either. IS project organization is largely hierarchical, it encourages projects to maintain an inward view and allows program management to allocate resources and keep a schedule of their own bundle of projects. It leaves it to the organization-wide central IS organization to keep an inventory of their portfolio of projects for strategic planning purposes (Olson 2004).

The need for different types of knowledge as suggested by Desouza and Evaristo is not well aligned with the IS project management organization since the latter enforces the boundaries of projects and their governing programs. Rather, Desouza and Evaristo's model requires a flatter view of the organization that allows individual projects to look at the wider organization beyond their immediate project and even program boundaries. This study investigates whether projects follow a closed pattern that focuses on the happenings of a project and are governed by a program structure, or an open innovation pattern that is flatter and includes more elements that are typically excluded from IS project management methodologies.

\section{OPEN INNOVATION AND ACTOR NETWORK THEORY}

Open innovation calls for going beyond the familiar inward look of innovation to explore different possibilities. It argues that the predetermined, closed boundaries around 
innovation are something from the past and detects the change in the innovation process and the erosion of these boundaries. Open innovation analyzes the organization on three levels: within the firm, between firms, and within the surrounding institutional environment (Chesbrough et al. 2006). This study focuses on detecting and analyzing the open innovation model in IS project management practices in order to investigate the implication of this line of thinking on the IS organization. Therefore, a flexible framework is needed that allows phenomena to reveal itself in its empirical setting. Actor network theory is found to meet such criteria.

ANT adopts a symmetrical view of sociological dichotomies, such as those between global and local, and macro and micro phenomena. It regards the sociotechnical world as not having a fixed, unchanging scale, and understands that "it is not the observer's job to remedy this state of affairs" (Latour 1991, p. 119). The theory does not see any difference in kind between the macro-structure and the micro-structure, so treats both with the same analytical tool. Latour (1991, p. 119) emphasizes that "respecting such changes of scale, induced by the actors themselves, is just as important as respecting the displacement of translations." In that sense, ANT is largely empirical. It does not impose any a priori structure on actors. On the contrary, it follows actors in their construction, modification, and negotiation of their macro- and micro-structures.

ANT also treats the distinction of inside and outside as open to question and negotiation. It therefore leaves it to actors to define what is inside and what is outside and the boundary between them (Law 1992). Actors also define one another in their interaction (Callon 1991). By defining what is local and inside, actors try to create a negotiation space, a notion seen as having two essential characteristics: it is a private area, physical and/or metaphorical, that is relatively inaccessible to those outside; it is an area in which plans, ideas, designs, and/or possibilities with implications for control of the outside world may be generated, explored, and tested in a way that is largely invisible to those on the outside (Law 1992). The negotiation space thus represents an area of relative autonomy approved by actors in the global network in order to build a local network. The establishment of a negotiation space is one of the strategies that actors adopt in order to build stable networks of sociotechnical objects. Law and Callon (1988) explain that a negotiation space makes it possible for mistakes to occur in private; within a negotiation space, it is also possible to experiment and, if all goes well, it is possible to create relatively durable sociotechnical combinations.

Continuous work and many negotiations take place on the boundary between the global and local or the outside and inside in order to secure the existence of the inside. For example, in his book Science in Action, Latour identified the inside as the laboratory itself, with all its heterogeneous combinations of scientists, machines, and natural phenomena. On the other hand, the outside of the laboratory is the combination of financial institutions, governments, and others. The internal/external division becomes the provisional outcome of a relationship between the outside recruitment of interests and the inside recruitment of new allies that "each step along the path the constitution of what is 'inside' and what is 'outside' alters" (Latour 1987, p. 159).

ANT has been found useful in providing "a very good way of telling stories about 'what happens out there' that defamiliarizes what we may otherwise take for granted" (Calas and Smircich 1999, p. 663). Therefore, it is applied in this study alongside the open innovation concepts to unwrap the structural dynamic of the IS project beyond the 
prespecified structure of IS project and program as presented in different IS project management methodologies.

\section{RESEARCH METHODOLOGY}

\subsection{Research Method}

This study follows the interpretive tradition of research. Interpretive research does not predefine dependent and independent variables, but focuses on the complexity of human sense making as situations emerge (Kaplan and Maxwell 1994). Interpretive methods of research in IS are aimed at producing an understanding of the context of the information system, and the process whereby the information system influences and is influenced by the context (Walsham 1993, p. 4). This study examines the open innovation phenomenon in IS organization through a single case study. In doing so, it does not seek any statistical generalization but allows for insight and theoretical generalization to be drawn (Walsham 1995).

Data collection took place between February 2001 and October 2001; follow-up phone calls, e-mails, and short meetings were conducted through February 2002. Data were collected through semi-structured interviews with 34 informants. Data were also collected through participant observation, with the researcher attending most of the configuration sessions and project meetings in different organizational levels. The researcher also participated in social events, conferences, and different organization-wide events and was copied in most project e-mail correspondence.

Data was analyzed and grouped first according to the traditional structure of project management specified in methodologies into project, program, or corporate IS governance (Miles and Huberman 1994). A chart has been drawn of issues that crossed these boundaries. New charts have been drawn of each issue crossing the traditional boundaries identifying actors involved, negotiation, and resolution. Special attention has been taken to identify the negotiation space, its settling, and where it settles.

\subsection{The Case of Posta}

Posta is a large European postal and parcel-delivery services company. It provides national and international mail services and handles over 75 million items every day. The cost of its SAP project was around $\$ 114$ million. This study focuses on examining the course of the financial project. The financial project aimed to implement SAP financial modules that include finance, material management, assets management, PS, and eprocurement in 100 different locations within the country. The total number of users reached was over 11,000 .

The financial project was planned to take 30 month and be released (local implementation) in three phases. The first phase covered four business units and served around 4,000 users. This phase was initially planned to go live on May 1, 2001. However, it was rescheduled to go live three month late at the end of July 2001. The second phase covered eight business units and about 6,000 users. It was initially scheduled to go live 
on September 1, 2001. In order to accommodate the slippage of the first phase, however, its deadline moved to end of October 2001, then was delayed again to the end of November 2001. The third phase was planned initially to go live the first week of January 2002, and had not been formally moved to a later date, even though last contact with the organization was at the end of February 2002.

\section{RESEARCH FINDINGS}

The SAP finance project's management was under the umbrella of a program called Enterprise Systems. This is in line with PRINCE methodology and the wisdom of bundling related projects under the governance of a program organization. The program included four projects: a human resources project to implement the HR module of SAP, a finance project to implement finance modules of SAP, and a decision support project to implement an off-the-shelf decision support system and infrastructure project. The following sections present the interaction between the finance project and others in the organization. It follows the IS project management's predefined hierarchical structure of project and program and inside and outside to reveal the erosion of this rigid view and its traditional boundaries.

\subsection{Within the Program}

\subsubsection{Allocating Resources or Recruiting Allies}

The finance, HR, and infrastructure projects were launched at the same time and were managed under a multiproject program called enterprise systems. The finance and HR projects were colocated in the same building. The finance project, sponsored by a senior director from Finance, was problematized as "essential for the survival of Posta." The director actively convinced the organization that the "executive board [believes] that without this program we won't survive, we won't manage the group." The financial project network aligned the most powerful top management in Posta, who all had a financial background or were from the finance community. These powerful allies supported the finance project in securing a generous three floors of desk space in the building. They also backed and promoted the finance project in different departments, encouraging employees to join this powerful network and to join the finance project on a secondment basis.

The finance project succeeded to interest and enrol "sufficient internal resources" in terms of human expertise, desk space for their teams, and management support. On the other hand, the HR project found it difficult to compete with such a powerful project. It struggled to find sufficient desk space in the same building as the finance project, and 25 percent of its team did not have their own permanent personal desk space and had to "hot desk."1 The HR project also could not recruit sufficient staff as staff preferred to be seconded to the finance project.

${ }^{1}$ Rotating and using any empty desk available that day. 
The HR project complained to the enterprise systems program board that it was not able to "operate efficiently and cost effectively," particularly when some of its staff had no desk space and needed to spend hours every day trying to find suitable workspace. The board recognized the problem and commented, "indeed productivity may well suffer if the early part of the days are spent in the search for a hot desk which, when found, is unlikely to be close to the people with whom the individual needs to relate in work terms" and that "efficiency, effectiveness and costs are all likely to be adversely impacted" (from the minutes of a board meeting). Yet the board could not find a solution for the problem and gently asked the finance project to help out. The board also recognized that the HR project had a serious staff shortage and was unable to fill many of the vacancies. These problems persisted until the later termination of the HR project due to a budget reduction and prioritization exercise.

\subsubsection{Negotiating Program Methodology}

The enterprise systems program followed the Posta tradition of managing projects using the PRINCE methodology. It used PRINCE to manage its portfolio of projects and assumed it would be the uniform methodology for project management for all IT projects under its governance. The finance project was profoundly enrolled and recruited in the SAP network of SAP implementation methodology (ASAP) and SAP-certified consultants. Thus, the finance projects resisted the adoption of the PRINCE methodology and negotiated in favor of SAP's implementation methodology, ASAP.

The SAP system and the SAP company placed the ASAP methodology as the passage point for its implementation, drawing on the complexity of the system and the company's intense experience in developing different versions of it and implementing SAP in different contexts. In addition, the SAP-certified consultants who worked as the external consultants that comprised part of the finance project team also problematized the issue and fixed ASAP as the only way forward, commenting, "we've been there before, we saw the best and worse...this [SAP] is different, no way to implement it with PRINCE. We are here to deliver. If you use PRINCE, we cannot guarantee delivery." The program's problematization of consistency and uniformity was weaker than the SAP vendor's and external consultants' problematization of survival, ensuring delivery, and achieving the promised good results.

Furthermore, the internal teams of the SAP project, being enrolled in the SAP network, cautioned the program board against using PRINCE. They argued that it would "waste a lot of time and won't guarantee anything really." They also argued "if we use PRINCE, it would take us ten years or more to implement SAP. Do we have time?" This left the board with no way but to accept the use of the ASAP methodology despite its differences with the program methodology and Posta's tradition of using PRINCE. The program management continued to use PRINCE to govern the program.

The finance project created an unexpected boundary between itself and its governing body. This boundary, based on the use of a different methodology, deviates from the prescriptive IS project management literature. 


\subsection{Outside the Program}

\subsubsection{Negotiating Functions and Technical Components}

While the finance project based on SAP was underway, there was another project in Posta called the customer relationship management project (CRM) to implement Siebel's CRM system. Both projects were taking place at the same time yet each had its own project and program management structure and hence there was no relationship between them. In February 2001, when the SAP financial system moved to the realization phase, one of the technical components that had been taken for granted-the customer database - was discovered to be held in the Siebel system. The finance project management had no idea beforehand that this database was one of the areas in the domain of the CRM project and that acquiring it would become a subject of negotiation. This jeopardized the billing functionality of the SAP system. The issue was raised first with the finance project's program board, who thought that the issue was "simple, we need it [the database] in a certain time, IS strategy will ensure this." The issue was then raised with the corporate IS strategy - the governing body of corporate IS portfolio - to "immediately resolve." IS strategy liaised between the two networks and when this did not work, they organized several negotiation meetings with the two (finance and CRM) project management teams.

The timing of the delivery of the customer database continued to be a highly debatable issue between the two projects. For the CRM team, the "push forward" of the "customer engine" (the customer database) that the SAP project asked for was not possible. The CRM actors, including technology requirements and methodology, had a different time frame for developing this database than did the SAP project network and refused to jeopardize its system.

The CRM issue that emerged started to shadow most of the configuration sessions of the finance project. Senior users kept asking questions regarding the data and where it would be held. Senior users recognized the need to establish a communication channel with the CRM. The arguments concerning what data would (and would not) be stored within the CRM system included statements such as: "there is no way that this [data] would be held there [in the CRM], it has to be in the finance system"; "we have to negotiate this with them [CRM project]"; "let's clarify what they are doing." The finance project was also concerned about how much visibility (access) would be allowed between the financial system and the CRM. In particular, the position of the billing queries part of the SAP system needed to be clarified as this required access via a SAP front to a Siebel database. The finance project raised this issue with the enterprise systems program and the business unit sponsoring the CRM was contacted. After some negotiation between the finance project, the enterprise system program, and this business unit, an agreement "allowing full visibility between the SAP billing database and the details [of customers] on the Siebel pricing database" was reached.

The enterprise systems program and the finance project initially maintained that "it is indispensable" for the customer database to meet the SAP schedule, but after a lengthy process of negotiation it realized that the CRM "won't finish for the time [they] wanted." Thus, the finance project, and enterprise system program settled with doing "many interfaces with old systems" until the CRM project delivered the pricing engine, which 
was due in December 2002. This meant that the finance project had to create many workarounds until its go-live date (scheduled in February 2002) and delay work on delivering full functionality of the implemented system until after CRM delivers the pricing engine (expected in December 2002). At the time the researcher left the field work, there was speculation suggesting that a fully functional finance system would not be delivered before March 2003, causing a delay of over a year for the finance project.

Realizing the importance of recruiting the CRM network into the finance project network, a CRM representative was later invited to attend the finance project's board meetings. He was given full membership on that board in order to "bring in views about what [was] happening in the CRM" and to "ensure full integration of the finance project with the CRM."

The traditional structure of project, program, and IS corporate governing body that defines boundaries for the realm of project, program, and central management could not achieve a particular resolution for the CRM issue. It was down to both projects (finance and CRM) to negotiate functionality, components, and delivery time. When they needed to negotiate visibility, the sponsoring business unit of CRM had to be included and agree to this issue since it became a financial matter and a question of whether the finance project should financially contribute to the CRM project as one of its beneficiaries. The hierarchy of IS project's governance had to be overcome to allow direct interaction between projects that previously seemed remote and unrelated.

\subsubsection{Negotiating the Organization Structure}

SAP in Posta was initiated as an outcome of an organization-wide restructuring program that began in 1998. In June 2000, the government enforced something new when it published a report that stated, "Posta should urgently take forward work to maximize the...efficiency of network operation." The government allocated $£ 270$ million for Posta to implement the report's recommendations over the following three years. To achieve the necessary efficient performance, Posta identified the urgent need to change the structure of its three distribution business units. The restructuring program suggested an initiative that would involve redesigning the three distribution business units and their amalgamation into one unit.

In February 2001, rumors started to spread within Posta that the organizational structure might change again and that the Posta board was studying the creation of a new entity, known here anonymously as "distribution unit." The three distribution business units that were said to be part of further restructuring (if the rumored new distribution unit came about) constituted the majority of phase one of the finance system implementation as the latter was comprised of four business units. The finance project team was also in contact with the business units at that time in order to finalize their requirements. The finance project director heard the rumor about the distribution unit and thought to find out something more definite in discussions with the enterprise system program director. The enterprise system program board met to discuss the issue and to assess the impact of creating this new business unit on the finance project but it could not confirm what would happen and "the impact assessment [was] deferred until the situation is clarified" (minutes of an enterprise system program board meeting). 
In March 2001, the finance project director arranged a general meeting to announce that "as nothing is confirmed yet, we will go on with the financial project as it is." Accordingly, in April 2001, the finance project team contacted the three distribution units and prepared sessions to sign off their business requirements, although the project team realized that their requirements were evolving and what they agreed on at that time was subject to "potential... significant rework" (interview with project manager).

In June 2001, the Posta Board announced the creation of the distribution unit as a new business unit, incorporating three of the existing distribution BUs, with the aim of having it fully operational by the end of September 2001. Since the organizational redesign wouldn't be final before September 2001, the finance project board was aware that "the window of opportunity for finalizing their optimum design is diminishing, even if it is to be included in phase three of the system build (instead of the planned phase one)." Hence, the finance project agreed with the three distribution units involved in the reengineering that they should implement a "tactical solution...to meet their current immediate requirements subject to later changes." The finance project was aware that "many changes to the current thinking [would] occur and that many things in the system built would be undone when the final organization design [is] complete" (interview with the financial project's director and comments at a project board meeting and program board update meeting).

This shows that events outside Posta, such as a government report and corporate response of restructuring has become an internal matter for the finance project, crossing traditional organizational boundaries and structure. The finance project at the start followed the traditional, closed innovation model of raising the matter to its program management but this did not pay off. The enterprise system program had no means within the closed model to seek high-level information regarding organization strategy and structure. So the finance project had to negotiate the matter directly with the business units affected to agree on a temporary solution and account for the delay and further rework on the system after going live. In effect, the finance project had to break its predetermined organizational boundary to decide on its future course of action since the whole matter was beyond its program and even corporate IS strategy unit.

\section{ANALYSIS: CLOSED OR OPEN INNOVATION?}

This paper started by questioning the validity of the open innovation concept in IS projects as opposed to the closed model provided by IS project management methodologies. Through a case study of an ERP implementation in an international organization, we have observed that the traditional boundaries prespecified by project management methodologies were continually crossed. The case study reveals that the project boundaries themselves are malleable and negotiable and a project should be seen in the light of other projects within the organization. An IS project cannot be seen as only a single instance within the organization, the focus taken by most IS literature. Indeed, modern organizations present a busy platform where several projects take place at any point in time. The control notion that projects should be isolated and internally managed-as echoed in project management methodologies - misses the complexity of organizational 


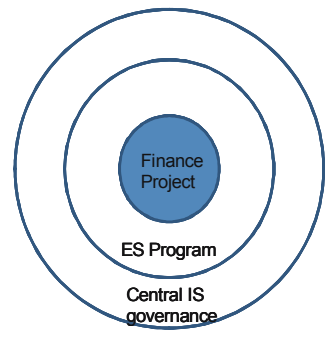

Closed Innovation View of Finance Project

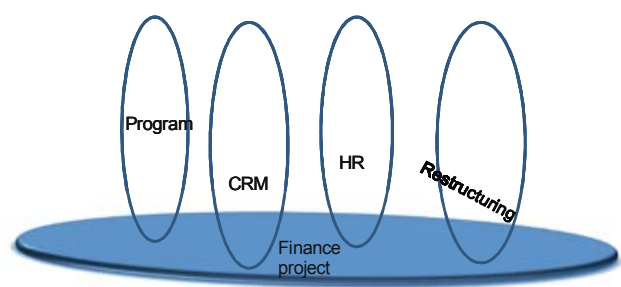

Open Innovation View of Finance Project

\section{Figure 1. Alternative Conceptualizations of the Finance Project}

innovation. The reliance on integrated systems that oversee entire processes through what used to be traditionally separated functions and the complexity of these crossfunctional, integrated software projects and their reliance on their particular implementation methodologies invites the inclusion of many different parties that were seen as outsiders in the closed model. Modern IS projects can no longer isolate themselves from the rest of the organization, relying on a lengthy command and control organizational structure. Projects need to overcome these barriers, to interact with each other in a horizontal manner.

The case study also shows that an IS project cannot isolate itself following a closed model for innovation where project management is defined by WBS, OBS, and a scheduling tool. The studied project extends its interaction beyond those boundaries to create its network of allies and finds ways to work collaboratively with them. The latter is in line with the open innovation model.

Figure 1 contrasts the closed innovation model, stemming from IS project management methodologies, with the open innovation model as observed in the studied case. The open innovation view of the finance project presents a network view of the project where the project seeks alliances, competes, and collaborates and in all cases negotiates with parties including (1) another project (HR) that traditionally was seen as part of the bundle of projects managed under one program (enterprise system), (2) its program management that was traditionally viewed as its governing body, (3) aother bundle of projects running under the management of a different program that was viewed in the traditional IS project management as a remote project under the governance of an IS corporate management, and (4) a corporate restructuring program that, in the traditional IS project management, was out of the realm of IS.

We have been observed in the case study that despite the existence of a traditional program management represented by the enterprise system program, colocated projects such as finance and HR continued to compete over resources. This contrasts with the stance of IS methodologies that the governance of a program ensures the fair allocation of resources between the projects involved (Cadle and Yeates 2004, pp. 52-62). The case study shows, in line with ANT propositions, that it is up to the individual project to extend its boundary and recruit powerful allies (Latour 1986, 1996). The prespecified project management structure of project and program has in effect little influence over project behavior. The finance project aligned powerful actors and created a favorable 
image within the organization that made potential recruits willing to join it rather than the low-key HR project. These powerful allies also helped the finance project to secure generous desk space. In effect, the HR project found itself in a weak competitive position where it had to request help from the program board. The program board could not interfere with the powerful network of corporate executives that the finance project recruited or with the image it created of itself as being "essential for the survival" of the company in the future. Therefore the enterprise system program role was limited to recognizing the problem and gently requesting that the finance project help without putting any pressure on it. The competition between HR and finance denies the view of IS project management methodologies of control over resource allocation between projects based on a command and control model that assumes projects have strict boundaries and program management will be able to exercise power over its managed projects to distribute resources. In contrast, the case study supports the ANT model of network building and negotiation (Latour 1996). It shows that each project has, in principle, the possibility to scale itself up through the creation of powerful allies. In doing so, a project bypasses the traditional, mundane organizational structure imposed by the closed model of project management. It asserts that an IS project is an open innovation that crosses traditional boundaries to recruit different actors that contribute to its success.

The assumption that program methodology presents a global context outside the project's control and that projects should only follow their governing program is also in doubt. The case study illustrated that off-the-shelf packages and, in particular, large integrated systems such as SAP come to organizations with their own methodology and support network. Implementing such a system would bring a well-established network to the organization, enhancing the negotiation power of such a project. As the case study shows, the finance project, supported by the SAP network, managed to create a negotiation space between itself and its governing program to debate its managing methodology. This process shifted the project management methodology to be an inside matter for the finance project to decide upon and not to be ruled by its governing body, the enterprise system program. This is in line with ANT proposition that the inside and outside are negotiated and it is up to actors to decide what is inside and what is outside (Law 1992). This supports the open innovation model, where a project such as ERP extends beyond the organization boundary to include partners and allies (Chesbrough 2003), then negotiates and shifts its traditional boundary.

The billing function was supposed to be a local, private matter for the finance project. It was part of the SAP technology under implementation and hence was assumed to fell within its boundary. This view was in doubt when it was discovered that the customer data base that the SAP billing functionality relied upon was held in the Siebel system of the CRM project. What once appeared to be an inside matter for the finance project to decide turned out to be a point of negotiation that required the involvement of many external parties, including CRM project management, the CRM business unit sponsor, and corporate strategy. Within an open innovation model, no boundaries are guaranteed or immune. Boundaries cannot be black boxed (Vidgen and McMaster 1996), any could be opened and negotiated and new ones created accordingly. In the studied case, the negotiation ended by agreeing that the customer data base would continue to be held in Siebel and the finance project would create work-arounds to achieve semifunctional billing until the implementation of its last phase, when it would interface the 
SAP system with the Siebel system to configure a final solution for the billing function. The finance project decided afterward to collaborate with the CRM project and have a member of staff from the CRM regularly attend the finance project meetings. The need for both projects to collaborate is not supported by the methodologies. It represents a new phenomenon where participants in the field found the closed innovation model unsupportive and intuitively decided that collaborating would be more productive so they decided to exchange representatives. This finding supports the open innovation view of breaking the silos and actively seeking collaboration.

Organization structure used to be seen as a context for project implementation and part of the business requirements that need to be specified and captured in the early stages of the project. In Posta, there was another program taking place to restructuring the organization. The finance project, when faced with the rumors regarding change of organizational structure, followed the traditional project structure of raising the issue with its enterprise system program, which in turn raised it with corporate IS strategy. This route did not pay off and the finance project had to open up its boundary to treat the affected business units as partners (not clients, as in the traditional view), to discuss with them possibilities and a future course of action. This presents another instance where the open innovation model surfaced in the case study, with the project including its clients as partners and openly discussing with them the high uncertainty of the situation affecting project delivery and agreeing on a future scenario.

\section{CONCLUSION}

This study shows that large, integrated IS innovation follows in practice the advocated open innovation model and not the closed model that project management methodologies support. It reveals that project boundaries are flexible, changeable, and negotiable. There are no rigid, prespecified boundaries as project management assumed. In practice, IS projects are in constant negotiation of boundaries as different organizational actors emerge to renegotiate the previously set boundaries. Therefore, the inside and outside of the project are the result of negotiation rather than a preset decision of project management or program management. This negotiation and setting of boundaries tends to be a continuous activity rather than being static and imposed on IS project.

The study contributes to IS project management by uncovering the open space of innovation that an IS project sails through during its course. The perception of an IS project as an open innovation provides a dynamic, flatter view of IS project innovation and its management structure. It departs it from the silo view suggested by IS project management and the traditional organization of project and program. Accordingly, an individual IS project should actively and continuously span this open space to detect collaborators, rivals, and partners. This study provides an explanation of White and Fortune's (2002) study where 46 percent of respondents reported that their project gave rise to unexpected side effects or outputs and that nearly 70 percent of the side effects could be attributed either directly or indirectly to lack of awareness of the environment. They concluded that "this may imply that many of the tools and techniques the respondents used were poor at modeling 'real world' problems or that insufficient account was taken of project boundaries and environments" (p. 5). Indeed, this study shows that tools 
that focus on scheduling and cost are not enough to manage projects in the complex, open innovation space of today's organization. Mechanisms for spanning and scanning the project landscape need to be incorporated into project management practices and awareness needs to be increased that an IS project is no longer a local matter that can be treated as a closed innovation isolated from the rest of the organization. It should be noted that the inclusion of partnerships and alliances in the project does not always mean collaboration, but could bring rivalry that should be recognized and accounted for.

The study also contributes to the very thin strand of studies that consider the management of IS projects in multiple project environment. It provides a practice lens and theoretical grounding to the Desouza and Evaristo (2004) study on project knowledge management. Indeed, knowledge in and about projects should be exchanged and individual projects should actively scan the organizational open space for other projects that constitute possible collaborators, rivals, and partners. On the practice side, the study suggests the creation of a "project scout" role within each project to provide a broad view of the organization that crosses traditional boundaries and structures.

\section{References}

Cadle, J., and Yeates, D. 2004. Project Management for Information Systems $\left(4^{\text {th }}\right.$ ed.), New York: Prentice Hall/Financial Times

Calas, M. B., and Smircich, L. 1999. "Past Postmodernism? Reflections and Tentative Directions," Academy of Management Review (24:4), pp. 649-671.

Callon, M. 1991. "Techno-Economic Networks and Irreversibility," in A Sociology of Monsters: Essays on Power, Technology and Domination, J. Law (ed.), London: Routledge, pp. 132-161.

Chesbrough, H. 2003. Open Innovation: The New Imperative for Creating and Profiting from Technology, Boston: Harvard Business School Press.

Chesbrough, H., Vanhaverbeke, W., and West, J. (eds.). 2006. Open Innovation: Researching a New Paradigm, New York: Oxford University Press.

Cijsouw, R. S., Jorna, R. J., Rakhorst, G., and Verkerke, G. J. 2007. “Omissions in Managing Knowledge in Innovation Processes or How to Handle Knowledge, Humans, and Tasks: A Semio-Cognitive Approach," in Project Management and Risk Management in Complex Projects, P.-J. Charrel and D. Galarreta (eds.), Boston: Springer, pp. 15-45.

Damm, D., and Schindler, M. 2002. "Security Issues of a Knowledge Medium for Distributed Project Work," International Journal of Project Management (20), pp. 37-47.

Desouza, K. C., and Evaristo, J. R. 2004. "Managing Knowledge in Distributed Projects," Communications of the ACM (47:4), pp. 87-91.

Dooley, L., Lupton, G., and O’Sullivan, D. 2005. "Multiple Project Management: A Modern Competitive Necessity," Journal of Manufacturing Technology Management (15:4), pp. 466-482.

Evaristo, R., and van Fenema, P. C. 1999. “A Typology of Project Management: Emergence and Evolution of New Forms," International Journal of Project Management (17:5), pp. 275-281.

Garrety, K., Robertson, P. L., and Badham, R. 2004. "Integrating Communities of Practice in Technology Development Projects," International Journal of Project Management (22), pp. 351-358.

Gibbons, M., Limoges, C., Nowotny, H., Schwarzman, S., Scott, P., and Trow, M. 1994. The New Production of Knowledge, Newbury Park, CA: Sage Publications. 
Henriksen, H. Z., and Kautz, K. 2006. "An Analysis of IFIP TC8 WG 8.6: In Search of a Common Theoretical Denominator," in The Past and Future of Information Systems: 1976-2006 and Beyond, D. Avison, S. Elliot, J. Krogstie, and J. Pries-Heje (eds.), , Boston: Springer, pp. 143-152.

Hobday, M. 2000. "The Project-Based Organization: An Ideal Form for Managing Complex Products and Systems?," Research Policy (29), pp. 871-893.

Kaplan, B., and Maxwell, J. A. 1994. "Qualitative Research Methods for Evaluating Computer Information Systems," in Evaluating Health Care Information Systems: Methods and Applications, S. J. Jay (ed.), Thousand Oaks, CA: Sage Publications, pp. 45-68.

Latour, B. 1986. "The Powers of Association," in Power, Action and Belief: A New Sociology of Knowledge, J. Law (ed.), London: Routledge \& Kegan Paul, pp. 264-280.

Latour, B. 1987. Science in Action: How to Follow Scientists and Engineers Through Society, Cambridge, MA: Harvard University Press.

Latour, B. 1991. "Technology is Society Made Durable," in Sociology of Monsters: Essays on Power, Technology and Domination. J. Law (ed.), London: Routledge \& Kegan Paul, pp. 103-131.

Latour, B. 1996. Aramis or the Love of Technology, Boston: Harvard University Press.

Law, J. 1987. "Technology and Heterogeneous Engineering: The Case of the Portuguese Expansion," in The Social Construction of Technological Systems: New Directions in the Sociology and History of Technology, W. E. Bijker, T. P. Hughes, and T. Pinch (eds.), Cambridge, MA: MIT Press, pp. 111-134.

Law, J. 1992. "The Olympus 320 Engine: A Case Study in Design, Development, and Organizational Control," Technology and Culture (33:3), pp. 409-440.

Law, J., and Callon, M. 1988. "Engineering and Sociology in a Military Aircraft Project: A Network Analysis of Technological Change," Social Problems (35:3), pp. 284-297.

Masini, A., and Pich, M. T. 2004. "The Diffusion of Competing Technological Innovations in a Network: Exploration Versus Exploitation Revisited," working paper, London Business School WP OTM 04-021.

Meredith, J. R., and Mantel, J. S. 1995. Project Management: A Nanagerial Approach, New York: Wiley.

Miles, M. B., and Huberman, A. M. 1994. Qualitative Data Analysis: An Expanded Sourcebook, Newbury Park, CA: Sage Publications.

Olson, D. L. 2004. Introduction to Information Systems Project Management, New York: McGraw-Hill/Irwin.

Payne, J. H. 1995. "Management of Multiple Simultaneous Projects: A State-of-the-Art Review," International Journal of Project Management (13:3), pp. 163-168.

Rothwell, R. 1994. "Towards the Fifth-Generation Innovation Process," International Marketing Review (11:1), pp. 7-31.

Steyn, H. 2002. "Project Management Applications of the Theory of Constraints Beyond Critical Chain Scheduling," International Journal of Project Management (20), pp. 75-80.

Swan, J., and Scarbrough, H. 2005. "The Politics of Networked Innovation," Human Relations (58:7), pp. 913-943.

Vidgen, R., and McMaster, T. 1996. "Black Boxes, Non-Human Stakeholders and the Translation of IT Through Mediation," in Information Technology and Change in Organizational Work, W. J. Orlikowski, G. Walsham, M. R. Jones, and J. I. DeGross (eds.), London: Chapman and Hall, pp. 250-271.

Walsham, G. 1993. Interpreting Information Systems in Organizations, Chichester, UK: John Wiley \& Sons Ltd.

Walsham, G. 1995. "Interpretive Case Studies in IS Research: Nature and Method," European Journal of Information Systems (4), pp. 74-81. 
White, D., and Fortune, J. 2002. "Current Practice in Project Management: An Empirical Study," International Journal of Project Management (20),. pp. 1-11.

Wynn, E., and Fitzgerald, B. 2004. "IT Innovation for Adaptability and Competitiveness," in IT Innovation for Adaptability and Competitiveness, B. Fitzgerald and E. Wynn (eds.), Norwell, MA: Kluwer Academic Publishers, pp. xxv-xxxix.

\section{About the Author}

Amany Elbanna is a lecturer in information systems at the Business School at Loughborough University. Her current research is in the area of project management of large IS projects, packaged software implementation, and agile software development. Amany can be reached by e-mail at a.elbanna@lboro.ac.uk. 